\title{
Burden of Hepatitis B Viral Infection among Workers in a Tertiary Health Institution in Southwestern Nigeria
}

\author{
Odimayo Michael Simidele ${ }^{*}$, Ajayi Oladimeji², Adejoke Adijat Joseph1, \\ Victor Aduayi ${ }^{3}$, Nwadioha Ihenacho Samuel ${ }^{4}$
}

\begin{abstract}
${ }^{1}$ Department of Microbial Pathology, Faculty of Basic Clinical Sciences, University of Medical Sciences, Ondo City, Nigeria ${ }^{2}$ Department of Medicine, Faculty of Clinical Sciences, College of Medicine, Ekiti State University, Ado Ekiti, Nigeria ${ }^{3}$ Department of Medical Microbiology, Faculty of Basic and Allied Medical Sciences, Benue State University, Makurdi, Nigeria ${ }^{4}$ Department of Community Medicine, Faculty of Clinical Sciences, College of Medicine, Ekiti State University, Ado Ekiti, Nigeria Email: *simideledimayo@gmail.com
\end{abstract}

How to cite this paper: Simidele, O.M. Oladimeji, A., Joseph, A.A., Aduayi, V. and Samuel, N.I. (2018) Burden of Hepatitis B Viral Infection among Workers in a Tertiary Health Institution in Southwestern Nigeria. Open Journal of Medical Microbiology, 8, 85-97.

https://doi.org/10.4236/ojmm.2018.84008

Received: August 16, 2018

Accepted: October 17, 2018

Published: October 20, 2018

Copyright $(9) 2018$ by authors and Scientific Research Publishing Inc. This work is licensed under the Creative Commons Attribution International License (CC BY 4.0).

http://creativecommons.org/licenses/by/4.0/

\begin{abstract}
Background: Health care workers (HCWs) are particularly at risk of hepatitis B virus (HBV) infections due to contact with infectious material like contaminated blood and body fluids or contact with HBV contaminated fomites. $\mathrm{HBV}$ vaccine is efficient in preventing infection though $5 \%-10 \%$ of individuals are non-responders. HBV vaccine was introduced into Nigerian childhood immunization services in year 2004. However, routine vaccination of HCWs is often not implemented due to cost in resource limited settings like ours. Therapeutic options are also not affordable and available options do not guarantee complete cure. This study aimed at determining the burden of HBV infection among HCWs in Ekiti State University Teaching Hospital (EKSUTH), Ado Ekiti, Nigeria, in order to institute prompt treatment as a way of curbing HBV spread and disease progression. Materials and Method: This cross-sectional study was conducted between October and December, 2016. Staff from various cadres in EKSUTH, who accepted to participate, was recruited into the study. Following informed consent, $5 \mathrm{mls}$ of blood collected from each participant was screened for HBV markers using HBV serologic combo test kit. Demography and Information on risk factors were collected with questionnaire. Results: A total of 965 participants, of which 323 (33.5\%) were males and 642 (66.5\%) were females, were recruited. Majority (72.6\%) were married. History of unprotected sexual contact and multiple sexual partners was found in $62.3 \%$ and $54 \%$ of participants, respectively. In this study, 43 (4.5\%) were HBsAg positive, out of which 40 (93\%) had HBV infection ( $\mathrm{HBcAb}$ positive). Prevalence of $\mathrm{HBV}$ infection was significantly higher
\end{abstract}


among males than females ( $\mathrm{p}$ value 0.004 ). Majority $(60.5 \%)$ of infected individuals were 30 to 49 years of age. All infected participants had no previous vaccination, but no serologic evidence of previous vaccination was seen among vaccinated individuals. Conclusion and Recommendation: We concluded that Hepatitis B virus infection is still high among HCWs and significantly higher among males than females. Vaccinated individuals were found to be HBsAg negative, but had no detectable protective immunoglobulin against $\mathrm{HBV}$. We recommend pre-employment screening and free vaccination of all staff in our health institutions, post vaccination immunization status assessment and provision of standard and affordable treatment for infected individual in order to achieve vision 2030 of HBV eradication.

\section{Keywords}

Hepatitis B Virus, Healthcare Workers, Immunization, Post-Vaccination Assessment

\section{Introduction}

Hepatitis, a systemic disease of the liver, mainly of viral origin, may be asymptomatic, or present with fever, nausea, vomiting, right hypochondriac pain, jaundice etc. [1]. It presents as an acute or chronic disease. Implicated in the acute disease are the five known hepatitis viruses designated A, B, C, D, E and less commonly, other viruses which cause hepatitis that cannot be ascribed to known agents, are hence called non A - E hepatitis. Hepatitis B virus (HBV) is a hepadnavirus implicated in chronic infections. Its transmission is parenteral and has a high prevalence, especially in Sub-Saharan Africa [2]. HBV has an inner nucleocapsid core that contains the hepatitis B virus core antigen ( $\mathrm{HBcAg}$ ) surrounded by an envelope which contains the hepatitis $B$ virus surface antigen (HBsAg) [3]. HBV has been found to have three morphologic forms seen on electron microscopy: the spherical particles, tubular or filamentous form and the Dane particles [3]. Its genome is partially double stranded, circular DNA made up of a positive stranded, short or $\mathrm{S}$ strand and a negative stranded, long or $\mathrm{L}$ strand [4]. The full length L strand is homologous to all HBV mRNAs while the $\mathrm{S}$ strand is variable, making up $50 \%-80 \%$ of the unit length [4].

$\mathrm{HBV}$ is worldwide in distribution with its prevalence highest in Sub-Saharan Africa (SSA) and East Asia and about 5\% - 10\% of the adult population in these places are chronically infected [5]. SSA, in which Nigeria is a country, has a high prevalence of infections, especially among health care workers (HCWs) who are particularly at increased risk of the infection by virtue of their occupation. For this reason, HCWs are routinely vaccinated against $\mathrm{HBV}$, but this is often not implemented in due to the cost of procurement of the vaccine and HCWs who desire to be vaccinated have to pay for it [6]. Prevention of HBV infection is cheaper than treatment, and equally important, especially in resource limited 
settings like ours, where therapeutic options are both scarce and unaffordable for the general populace [7]. Available treatment options also do not provide complete cure. Hence, prevention of infection is vital [7]. In populations with high HBV prevalence, most HBV transmission occurred during childhood. A significant proportion of the people however remain susceptible to the infection. Hence, there is the risk of contracting it irrespective of age [8].

Worldwide about 1 million deaths annually are attributed to HBV-related liver disease and hepatocellular carcinoma (HCC) [9]. It has been reported that approximately $30 \%$ of the world's population have serologic evidence of current or past HBV infection with a high proportion of chronic HBV carriers worldwide currently estimated at 400 million individuals. This fact and the attendant complications notably liver cirrhosis and HCC makes HBV infection a disease of major public health importance worldwide [10] [11] [12].

HBV infection as an occupational hazard in HCWs is a well-documented phenomenon, and it is dependent on the frequency of percutaneous and permucosal exposure to blood which commonly occurs due to needle or other sharp device injuries (NSIs), or contact with infected body fluids such as saliva, semen, etc. [13]. The frequency of HCWs exposure to HBV is influenced by HBV endemicity in the geographical location [13]. Other at risk groups are institutionalised persons, organ transplant patients, newborn infants of mothers with HBV positivity, recipients of unscreened blood, tattooing or ear piercing [9], men who have sex with other men, intravenous drug users, people with multiple sex partners, renal transplant patients, diabetics 60 years and above, and travellers to countries with a high incidence of HBV infection [14].

Preventive vaccination against HBV for hospital staff is standard in many countries, but is still not implemented in many resources-poor settings [6]. There have been reports of weak immune responses to $\mathrm{HBV}$ vaccination caused by, for example, diabetes or a current viral infection. $5 \%-10 \%$ of vaccinated individuals are known to be non-responders [6]. The WHO therefore recommends to monitor immune responses to the vaccine in addition to compulsory vaccination of HCWs [6]. The hepatitis B vaccine was included in the immunization schedule in Nigeria in 1995 but the vaccine only became widely available in 2004, when the WHO policy of including HBV vaccination in the routine immunization schedule for children was implemented.

The success of the immunization programme can be assessed by the timeliness of receipt of vaccines, the coverage of the vaccine and measurement of morbidity and mortality from the target disease [15]. Attention need to be paid to these factors to ensure an effective and successful vaccination process. According to the WHO, HBV vaccine has been introduced in 184 countries in the world with an average global vaccine coverage with 3 doses of hepatitis B vaccine estimated at $84 \%$, as high as $92 \%$ in the Western Pacific [16]. In Nigeria however, few studies conducted on estimating global coverage is in a serogroup of individuals, the HCWs and an average rate of $20 \%$ was reported in them. The 
risk of occupational exposure of these groups of individuals to HBV however remains high [17]. Mortality attributable to this preventable and curable infection is quite high, being a leading cause of death and disability worldwide. Unlike most communicable diseases, the absolute burden of viral hepatitis increased between 1990 and 2013 [18]. The availability of effective vaccines and treatments suggests an important opportunity to improve public health hence the need to find out the actual burden of the infection, the susceptible proportion of the population with the aim of instituting a prompt intervention. This study aimed at determining the prevalence and status of HBV infection among HCWs in Ekiti State University Teaching Hospital (EKSUTH), Ado Ekiti, Nigeria, in order to encourage commencement of prompt treatment as a way of limiting disease progression among infected individuals and curbing HBV spread in the populace.

\section{Subjects and Methods}

This cross-sectional study was conducted between October and December, 2016. Members of Staff from various cadres in EKSUTH, who accepted to participate, were recruited into the study. Following written informed consent, demography and Information on risk factors were collected from each participant using a self-administered questionnaire. Information collected include age, sex, marital status, primary place of abode, level of education, HBV exposure risks such as previous surgery, previous blood transfusion, tattoos, body piercings, scarification marks, regular use of condom or safe sex practices, number of sex partners, sexual preferences, intravenous drug use and previous history of sexually transmitted disease as well as previous hepatitis $B$ vaccination among others were collected. Each participant was screened for HBV markers using HBV ELISA test kit (Innovita, 2017), following manufacturer's instruction strictly. About 5 mls of venous blood was collected from the left arm of each participant into an EDTA bottle and the plasma was subsequently separated. Samples were either processed the same day or stored in a $-20^{\circ} \mathrm{C}$ refrigerator till the time of testing. Refrigerated samples were allowed to warm up to room temperature for at least 15 minutes before testing for HBV infection. Markers such as Hepatitis B surface antigen (HBsAg), Hepatitis B surface antibodies (HBsAb), Hepatitis B core antibody ( $\mathrm{HBcAb})$, Hepatitis $B$ envelope antigens ( $\mathrm{HBeAg}$ ) and Hepatitis $B$ envelope antibodies (HBeAb) were sought for and properly documented.

Individuals found to be HBsAg reactive were categorized as having infection. HBsAg reactive individuals with antibodies to core antigens were considered as chronically infected, those individuals with $\mathrm{HBeAg}$ were considered with active infection while those without $\mathrm{HBeAg}$ but with $\mathrm{HBeAb}$ were interpreted to be inactive carrier. Individuals with $\mathrm{HBsAb}$ but without $\mathrm{HBsAg}$ were interpreted as past infection or immunized. Individuals with suspected infection were referred for Hepatitis B viral load quantification and other investigations and treatment. HBsAg negative individuals were sent for HBV vaccination. Data were analyzed 
using the Statistical Package for Social Sciences version 11.0 (SPSS inc, Chicago, USA, 1999). Student $\mathrm{T}$ test was used to compare continuous variables while Chi square was used for comparison of categorical variables as well as to evaluate associations between HBV positivity and associated factors. Statistical significance was set at a p-value (probability value) of $<0.05$. Ethical clearance was sought and gotten from the Ethics and Research Committee of EKSUTH.

\section{Results}

A total of 965 individuals working in the hospital were screened. Among these HCWs, 323 were males and 642 were females with age ranging from 15 years to 65 years. The median age of respondents was 35 years (Table 1). Majority of respondents were urban dwellers $75.8 \%$ ) and about $72.6 \%$ were married. Table 2 shows that $74 \%$ of our subjects had no history of surgery, no alcohol consumption (85\%), no sharing of sharps (83\%) and no history of IV drug use (96\%). History of unprotected sexual contact and multiple sexual partners were found in $62 \%$ and $54 \%$ respectively. However $62.1 \%$ were previously vaccinated either at recruitment into the health facility or before employment at the hospital.

Table 1. Sociodemographic variables of respondents.

\begin{tabular}{|c|c|}
\hline Variables & Total (\%) \\
\hline \multicolumn{2}{|l|}{ Age group } \\
\hline$<20$ & $32(3.3)$ \\
\hline $20-29$ & $256(26.5)$ \\
\hline $30-39$ & $324(33.6)$ \\
\hline $40-49$ & $243(25.2)$ \\
\hline $50-59$ & $102(10.6)$ \\
\hline$\geq 60$ & $8(0.83)$ \\
\hline Median age of respondents & 35 years \\
\hline \multicolumn{2}{|l|}{ Sex } \\
\hline Male & $323(33.5)$ \\
\hline Female & $642(66.5)$ \\
\hline \multicolumn{2}{|l|}{ Marital Status } \\
\hline Single & $264(27.4)$ \\
\hline Married & $701(72.6)$ \\
\hline \multicolumn{2}{|l|}{ Occupation group } \\
\hline Health worker & $749(77.6)$ \\
\hline Student & $145(15.0)$ \\
\hline Security & $28(2.9)$ \\
\hline Others & $43(4.5)$ \\
\hline \multicolumn{2}{|l|}{ Primary place residence } \\
\hline Urban & $733(76)$ \\
\hline Rural & $232(24.0)$ \\
\hline
\end{tabular}


Table 2. Risk Factors Associated with HBV Infection.

\begin{tabular}{cccc}
\hline Factors & Yes & No & Don't know/not sure \\
\hline & $\mathbf{n}(\%)$ & n (\%) & n (\%) \\
\hline Previous Hep B vaccination & $599(62.1)$ & $307(31.8)$ & $59(6.1)$ \\
History of surgery & $254(26.3)$ & $711(73.7)$ & $0(0.0)$ \\
Alcohol consumption & $149(15.4)$ & $816(84.6)$ & $0(0.0)$ \\
Blood transfusion & $445(46.1)$ & $500(51.8)$ & $20(2.1)$ \\
Sharing of sharps & $78(8.1)$ & $801(83.0)$ & $86(8.9)$ \\
IV drug use & $40(4.1)$ & $925(95.9)$ & $0(0.0)$ \\
Multiple sexual partners & $521(54.0)$ & $444(46.0)$ & $0(0.0)$ \\
Dental procedure & $298(30.9)$ & $667(69.1)$ & $0(0.0)$ \\
Unprotected sex & $601(62.3)$ & $364(37.7)$ & $0(0.0)$ \\
\hline
\end{tabular}

Figure 1 shows the prevalence of HBsAg positivity, a total of 43 (4.5\%) were found to be positive for HBsAg. Among these, 40 (93\%) were actually infected as evidenced by $\mathrm{HBcAb}$ positivity.

Table 3 shows that 23 (60\%) of the seropositive individuals were aged between 30 to 49 years, though there was no significant difference in seropositivity across the various age groups, the seropositivity rate was highest (12.5\%) among individual less than 20 years of age. A slightly higher percentage of seropositivity was seen among urban dwellers (4.6\%) compared to rural dwellers (3.9\%), similarly, there was a higher prevalence seen among the married (4.6\%) than single (4.2\%) individuals recruited into this study. Majority, 26 (60.5\%) of infected individuals were 30 to 49 years of age. All infected participants had no previous vaccination. None of the vaccinated individuals had post vaccination testing done.

The percentage HBsAg seropositivity seen among males was $7.1 \%$ while that in females was $3.1 \%$ and the difference was statistically significant ( $p$ value 0.004 ) with males having 2.4 times increase in the odds of being infected compared with females [OR: 2.384 (95\% CI: 1.289 - 4.410)] (Table 4).

\section{Discussion}

Viral hepatitis is a leading cause of death and disability worldwide. Acute hepatitis infection, cirrhosis and liver cancer were the 10th leading cause of death worldwide in 1990, and the seventh leading cause of death in 2013. Indeed, the number of deaths worldwide attributable to viral hepatitis increased by $63 \%$ from 1990 to 2013 [18].

A HBV prevalence of $4.5 \%$ was reported among HCW in this study. In a similar study, in Lagos, South West, Nigeria, a lower prevalence of $1.5 \%$ was reported though among doctors and nurses believed to be more vulnerable to the infection than other health workers. Ola et al. reported a higher prevalence of 13\% in Nigerian healthcare workers [19]. In Tanzania, where a similarity exists 


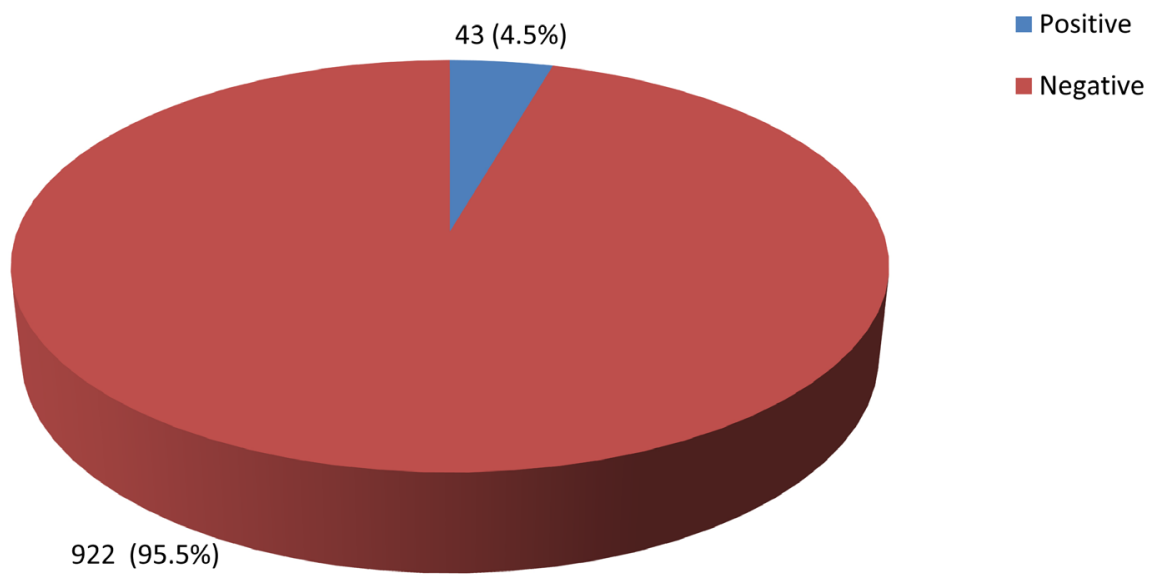

Figure 1. Prevalence of HBsAg positivity.

Table 3. Sociodemographic Correlates of HBV Seropositivity.

\begin{tabular}{|c|c|c|c|c|c|}
\hline \multirow{3}{*}{ Variable } & \multicolumn{2}{|c|}{ Measure } & \multirow[b]{2}{*}{ Total } & \multirow[b]{2}{*}{$x^{2}$} & \multirow[b]{2}{*}{$\mathrm{p}$ value } \\
\hline & Positive & Negative & & & \\
\hline & $\mathrm{n}(\%)$ & $\mathrm{n}(\%)$ & $\mathrm{N}(\%)$ & & \\
\hline \multicolumn{6}{|c|}{ Age group } \\
\hline$<20$ & $4(12.5)$ & $28(87.5)$ & 32 & $4.005^{\mathrm{Y}}$ & 0.548 \\
\hline $20-29$ & $8(3.1)$ & $248(96.9)$ & 256 & & \\
\hline $30-39$ & $15(4.6)$ & $309(95.4)$ & 324 & & \\
\hline $40-49$ & $11(4.5)$ & $232(95.5)$ & 243 & & \\
\hline $50-59$ & $5(4.9)$ & $97(95.1)$ & 102 & & \\
\hline$\geq 60$ & $0(0.0)$ & $8(100.0)$ & 8 & & \\
\hline \multicolumn{6}{|c|}{ Median age of respondents; 35 years } \\
\hline \multicolumn{6}{|c|}{ Sex } \\
\hline Male & $23(7.1)$ & $300(92.9)$ & 323 & 8.098 & $0.004^{*}$ \\
\hline Female & $20(3.1)$ & $622(96.9)$ & 642 & & \\
\hline \multicolumn{6}{|c|}{ Marital Status } \\
\hline Single & $11(4.2)$ & $253(95.8)$ & 264 & 0.071 & 0.789 \\
\hline Married & $32(4.6)$ & $669(95.4)$ & 701 & & \\
\hline \multicolumn{6}{|c|}{ Occupation group } \\
\hline Health worker & $31(4.1)$ & $718(95.1)$ & 749 & $0.350^{\mathrm{Y}}$ & 0.950 \\
\hline Student & $7(4.8)$ & $138(95.2)$ & 145 & & \\
\hline Security & $2(7.1)$ & $26(92.9)$ & 28 & & \\
\hline Others & $3(7.0)$ & $40(93.0)$ & 43 & & \\
\hline \multicolumn{6}{|c|}{ Primary place residence } \\
\hline Urban & $34(4.6)$ & $699(95.4)$ & 733 & 0.239 & 0.625 \\
\hline Rural & $9(3.9)$ & $223(96.1)$ & 232 & & \\
\hline
\end{tabular}


Table 4. HBsAg Positivity Gender Correlates.

\begin{tabular}{ccccccc}
\hline \multirow{2}{*}{ Variable } & \multicolumn{7}{c}{ HBV } & OR $(95 \% \mathrm{CI})$ & $\chi^{2}$ & p value \\
\cline { 2 - 7 } & $\mathrm{n}(\%)$ & $\mathrm{n}(\%)$ & $\mathrm{N}(100.0 \%)$ & & & \\
\cline { 2 - 7 } & & Sex & & & \\
Male & $23(7.1)$ & $300(92.9)$ & 323 & $2.384(1.289-4.410)$ & 8.098 & $0.004^{*}$ \\
Female & $20(3.1)$ & $622(96.9)$ & 642 & & & \\
Total & $43(4.5)$ & $922(95.5)$ & 965 & & \\
\hline
\end{tabular}

OR: Odds ratio; 95\% CI: 95\% Confidence Interval; ${ }^{*}$ : p value $<0.05$.

with Nigeria in their Expanded Program on Immunization (EPI) program, a 7\% prevalence was reported among HCWs in a tertiary health care centre. Introduction of HBV vaccination routinely into their nation's EPI was also a recent development, 2002 precisely, similar to what is obtainable in Nigeria [6]. Kateera et al. in Rwanda reported a prevalence of $2.9 \%$ of chronic HBV infection using $\mathrm{HBsAg}$ positivity, and $1.3 \%$ anti-HCV-positivity among tertiary hospital employees [20]. Ziraba et al. found chronic HBV infection in $8.1 \%$ of the HCWs in a central teaching hospital, Uganda [21]. The lower prevalence reported in this study may be due to vaccination as $62.1 \%$ of participants in this study were vaccinated at or prior to employment into the health facility.

Transmission is more in childhood and vaccine is effective in prevention of infection in the non-exposed or non-infected individual. In this study $62.1 \%$ of participants have been vaccinated at or prior to employment into the health facility but none ( $0 \%$ ) had serologic evidence of vaccination (HbsAb positivity). However, since none of them were positive for HbsAg it suggests that they were protected. None of our respondents had post vaccination testing, this is similar to the finding of Suckling et al. in Kenya where of the $12.8 \%$ HCWs previously vaccinated against $\mathrm{HBV}$, none checked their post vaccination status afterwards [22]. From the report of Vadas et al. from Johannesburg, South Africa up to $45 \%$ of HCW performed post vaccination testing. This may be related to the socio-economic characteristics of the studied population, this group of patients may be more enlightened than ours, however, availability of the test, and provision of publicly funded HBV treatment programme in South Africa may also play a role [23].

In a study carried out in Benue state to assess the prevalent serologic markers in that environment as well as group individuals into various clinical categories of current, acute or chronic infection, $85.9 \%$ of the analysed blood sample showed a serological evidence of exposure to HBV infection, some through natural infection (22.7\%) and others (13.0\%) through vaccination; $12 \%$ of those exposed were inferred to be currently infected and $91.2 \%$ chronically infected [24]. This study reported a $4.5 \%$ as having serologic evidence of infection, none of them had proof of vaccination, and none were healed. Apparently healthy in- 
dividuals with $\mathrm{HBV}$ infection are reservoirs of $\mathrm{HBV}$ which may serve as source of infection to other HCWs and patients.

In this study, the various risk factors were not found to significantly affect the prevalence of infection, this is similar to the findings of Amazigo $\mathrm{UO}$ and Chime $\mathrm{AB}$ in the eastern part of Nigeria where the risk factors predisposing to $\mathrm{HBV}$ infection were considered and found no positive correlation between the frequency of HBV markers and the history of blood transfusions, making the researcher to conclude that horizontal transmission aided by cultural or behavioral factors and clustering of carriers rather than transfusions is the main determinant of HBV prevalence in rural Nigeria [25]. In this study it appears a more common factor of working in hospital environment binds our subjects together thereby making other social factors less relevant. The main risk factor for HBV infection for HCWs is direct contact with infected material such as blood, body fluids, or needle stick injury hence HCWs are at particularly increased risk of infection [26].

Place of primary abode, whether rural or urban was found not to significantly influence positivity or otherwise to $\mathrm{HBV}$ in the study. This is in contrast to the findings from a study in eastern Nigeria where serologic markers were compared in rural and urban dwellers. In that study, it was found that total HBV exposure rate, $\mathrm{HBsAg}$ carrier rate and previous exposure to $\mathrm{HBV}$ measured by the frequency of $\mathrm{HBcAb}$ alone were significantly higher in the rural population compared with the urban population [25]. A similar finding was reported in western Samoa where people living in rural areas were more likely to be infected than those living in urban areas [26]. On the other side, place of abode influenced the $\mathrm{HBV}$ infection rate reported from a study carried out in China where the prevalence rate in rural districts of the country were found to be significantly lower than the urban population [27].

By the age of 40 years, $87 \%$ of the Nigerian population was believed to have at least one HBV serologic marker [25]; this claim was however not substantiated by the findings in our study in which age was not a significant factor influencing infection. Gender however influenced the prevalence as $\mathrm{HBV}$ was positive in $7.1 \%$ of males as compared to $3.1 \%$ of females and this was found to be statistically significant. Likewise in the study carried out in China [18], no significant association was found between infection prevalence and age of respondents. Khan et al. however reported an association between gender and age, and HBV prevalence, noting that males were more frequently infected compared to the females with a positivity ratio of 2.14:1; and infection rate declined with increasing age. In that study, the age groups more commonly infected were the $41-50$, $51-60$ and 0 - 10. The elderly (aged > 60) were very less frequently infected. This is probably due to introduction of HBV vaccine into the routine vaccination schedule for children early. In a similar population based study carried out by Alavian et al. also in Iran, predictors of HBsAg or HBcAb positivity in multivariate analysis were reported to be older age and marriage and no significant differences was found in the disease prevalence between males and females [28]. 
The determination of serologic markers in this study using qualitative rather than quantitative methods is a major limitation for this study. This is because our inability to detect protective antibodies (HBsAb) among previously vaccinated subjects may be due to low level rather than complete absence of antibodies.

\section{Conclusion}

The burden of HBV is still high among health workers in this environment and significantly more among males than females. Though HBV protective antibodies were not detected, there was no HBV infection among vaccinated individuals.

\section{Recommendation}

We recommend continued health education, pre-employment screening and free vaccination of all staff in our health institutions. Determination of post vaccination immunization status should also be encouraged. A robust hepatitis B program where treatment is made affordable and standardized for infected individuals should be provided in order to achieve vision 2030 of HBV eradication.

\section{Role of Authors}

Odimayo Michael Simidele, Nwadioha Ihenacho Samuel and Ajayi Oladimeji conceptualized the work; Odimayo Michael Simidele, Ajayi Oladimeji and Victor Aduayi did the initial data collection and sample processing; Joseph Adejoke Adijat and Odimayo Michael Simidele developed the initial draft; Joseph Adejoke Adijat did the data analysis; all authors read, made input and agreed on the final manuscript.

\section{Source of Funding}

None.

\section{Conflicts of Interest}

Authors have disclosed no conflicts of interest.

\section{References}

[1] Ryder, S.D. and Beckingham, I.J. (2001) ABC of Diseases of Liver, Pancreas, and Biliary System: Acute Hepatitis. BMJ, 322, 151-153. https://doi.org/10.1136/bmj.322.7279.151

[2] Zuckerman, A.J. (1996) Hepatitis Viruses. In: Baron, S., Ed., Medical Microbiology, 4th Edition, University of Texas Medical Branch at Galveston, Galveston, TX.

[3] Nicoletta, P., Daniel, L. and Arie, J.Z. (2003) Hepatitis B. Perspectives in Medical Virology, 10, 31-97.

https://www.sciencedirect.com/science/article/pii/S016870690310002X https://doi.org/10.1016/S0168-7069(03)10002-X

[4] Sunbul, M. (2014) Hepatitis B Virus Genotypes: Global Distribution and Clinical Importance. World Journal of Gastroenterology, 20, 5427-5434. 
https://doi.org/10.3748/wjg.v20.i18.5427

[5] WHO. (2018) Hepatitis B. http://www.who.int/mediacentre/factsheets/fs204/en/

[6] Mueller, A., Stoetter, L., Kalluvya, S., Stich, A., Majinge, C., Weissbrich, B. and Kasang, C. (2015) Prevalence of Hepatitis B Virus Infection among Health Care Workers in a Tertiary Hospital in Tanzania. BMC Infectious Diseases, 15, 386. https://doi.org/10.1186/s12879-015-1129-Z

[7] Lavanchy, D. (2004) Hepatitis B Virus Epidemiology, Disease Burden, Treatment, and Current and Emerging Prevention and Control Measures. Journal of Viral Hepatitis, 11, 97-107. https://doi.org/10.1046/j.1365-2893.2003.00487.x

[8] Jha, A.K., Chadha, S., Bhalla, P. and Saini, S. (2012) Hepatitis B Infection in Microbiology Laboratory Workers: Prevalence, Vaccination, and Immunity Status. Hepatitis Research and Treatment, 2012, Article ID: 520362. https://doi.org/10.1155/2012/520362

[9] Brooks, G.F., Carroll, K.C., Butel, J.S., Morse, S.A., Mietzner, T.A., Brooks, G.F., et al. (2013) Hepatitis Viruses. In: Carroll, K.C., Butel, J.S., Morse, S.A. and Mietzner, T.A., Eds., Jawetz, Melnick, \& Adelberg's Medical Microbiology, 26th Edition, McGraw-Hill, New York.

[10] Odimayo, M.S., Nwadioha, S.I. and Utoo, P.M. (2015) Level of Awareness of Hepatitis B Viral Infection among a Subset of Makurdi Community in Benue State, Nigeria. BMRJ, 7, 28-34. https://doi.org/10.9734/BMRJ/2015/11864

[11] Institute of Medicine (US) Committee on Issues and Priorities for New Vaccine Development. New Vaccine Development Establishing Priorities: Volume II: Diseases of Importance in Developing Countries. Washington DC: National Academies Press (US); 1986. Appendix D-5, The Prospects for Immunizing Against Hepatitis B Virus. https://www.ncbi.nlm.nih.gov/books/NBK219056/

[12] Robinson, W.S. (2000) Hepadnaviridae. In: Mandel, G.L., Bennett, J.E. and Dolin, P., Eds., Principle and Practice of Infectious Diseases, 5th Edition, Churchill Livingstone, New York, 1652-1685.

[13] Hisham, Z., Mabrouk, E., Noura, S., Abdulaziz, Z. and Omar, E. (2013) Hepatitis B Vaccination Status among Healthcare Workers in a Tertiary Care Hospital in Tripoli, Libya. Journal of Infection and Public Health, 6, 246-251. https://doi.org/10.1016/j.jiph.2013.02.001

[14] Kahn, A. (2017) Hepatitis B. Healthline. https://www.healthline.com/health/hepatitis-b

[15] Ayebo, E.S. and Antoinette, O. (2014) Hepatitis B Infection among Nigerian Children Admitted to a Children's Emergency Room. African Health Sciences, 14, 377-383. https://doi.org/10.4314/ahs.v14i2.13

[16] WHO Fact Sheet. Immunization Coverage.

[17] Ogoina, D., Pondei, K. and Adetunji, B. (2014) Prevalence of Hepatitis B Vaccination among Health Care Workers in Nigeria in 2011-12. International Journal of Occupational and Environmental Medicine, 5, 51-56.

[18] Stanaway, J.D., Flaxman, A.D., Naghavi, M., Fitzmaurice, C., Vos, T., Abubakar, I., et al. (2013) The Global Burden of Viral Hepatitis from 1990 to 2013: Findings from the Global Burden of Disease Study. The Lancet, 388, 1081-1088. https://doi.org/10.1016/S0140-6736(16)30579-7

[19] Ola, S.O., Odaibo, G.N., Olaleye, O.D. and Ayoola, E.A. (2012) Hepatitis B and E Viral Infections among Nigerian Healthcare Workers. African Journal of Medicine and Medical Sciences, 41, 387-391. 
[20] Ziraba, A.K., Bwogi, J., Namale, A., Wainaina, C.W. and Mayanja-Kizza, H. (2010) Sero-Prevalence and Risk Factors for Hepatitis B Virus Infection among Health Care Workers in a Tertiary Hospital in Uganda. BMC Infectious Diseases, 10, 191. https://doi.org/10.1186/1471-2334-10-191

[21] Kateera, F., Walker, T.D., Mutesa, L., Mutabazi, V., Musabeyesu, E., Mukabatsinda, C., et al. (2015) Hepatitis B and C Seroprevalence among Health Care Workers in a Tertiary Hospital in Rwanda. Transactions of the Royal Society of Tropical Medicine and Hygiene, 109, 203-208. https://doi.org/10.1093/trstmh/trv004

[22] Suckling, R.M., Taegtmeyer, M., Nguku, P.M., Alabri, S.S., Kibaru, J., Chakaya, J.M., et al. (2006) Susceptibility of Health Care Workers in Kenya to Hepatitis B: New Strategies for Facilitating Vaccination Uptake. Journal of Hospital Infection, 64, 271-277. https://doi.org/10.1016/j.jhin.2006.06.024

[23] Abdul-Hakeem, O.A., Agunbiade, A.B., Badmos, K.B., Lesi, A.O., Lawal, A.O. and Alli, Q.O. (2016) Prevalence of HBsAg, Knowledge, and Vaccination Practice against Viral Hepatitis B Infection among Doctors and Nurses in a Secondary Health Care Facility in Lagos State, South-Western Nigeria. Pan African Medical Journal, 23, 160.

[24] Mbaawuaga, E., Iroegbu, C. and Ike, A. (2014) Hepatitis B Virus (HBV) Serological Patterns in Benue State, Nigeria. Open Journal of Medical Microbiology, 4, 1-10. https://doi.org/10.4236/ojmm.2014.41001

[25] Amazigo, U.O. and Chime, A.B. (1990) Hepatitis-B Virus Infection in Rural and Urban Populations of Eastern Nigeria: Prevalence of Serological Markers. East African Medical Journal, 67, 539-544.

[26] Gust, I.D., Dimirakakis, M., Faaiuso, S., Ainuu, J. and Zimmet, P. (1981) The Prevalence of Hepatitis B Infection amongst Urban and Rural Populations in Western Samoa. Journal of Hygiene, 86-87.

[27] Yang, S., et al. (2017) Prevalence and Influencing Factors of Hepatitis B among a Rural Residential Population in Zhejiang Province, China: A Cross-Sectional Study. BMJ Open, 7, e014947. https://doi.org/10.1136/bmjopen-2016-014947

[28] Alavian, S.M., Tabatabaei, S.V., Ghadimi, T., Beedrapour, F., Kafi-abad, S.A., Gharehbaghian, A. and Abolghasemi, H. (2012) Seroprevalence of Hepatitis B Virus Infection and Its Risk Factors in the West of Iran: A Population-Based Study. International Journal of Preventive Medicine, 3, 770-775. 


\section{Appendix 1: Questionnaire}

1) Bio-data: age (in years) __ Gender (please tick): Male ( ) Female ( );

2) Marital status (please tick): Married ( ), Single ( ), Divorced ( ), Widowed ( ), If divorced or widowed, since when?

3) Nature of marriage: Monogamy ( ) Polygamy ( ); if polygamy, how many wives?

4) Tribe A. Yoruba

B. Hausa

C. Igbo

D. Others

5) Nationality: A. Nigerian B. Others (Please specify)

6) Educational status A. No Formal Education ( ); B. Primary Education ( ); C. Secondary Education ( ); D. Undergraduate ( ); E. Graduate ( ).

7) Occupation (please state): Nature of work

8) Religion: Christianity ( ). Islam ( ). Traditional ( ). Others (Specify)

9) Previous risk exposure: (please tick as appropriate): previous blood transfusion ( ); previous surgery ( ); multiple sexual partners ( ); HBV positive spouse or sexual partners ( ); previous herbal marks ( ), scarification marks ( ); history of intravenous drug addiction ( ); age at first sexual contact (please state): ; previous needle prick injury ( ); previous involvement in rescue mission for bleeding accident cases ( )

10) Preventive efforts: have you had hepatitis vaccination before? Yes ( ), No ( ); If yes, Where , When How many times

11) Have you ever been tested for hepatitis B? Yes ( ); No ( ). If yes, Where , When How many times ; what was the result? Pos. ( ); Neg. ( ).

12) Have you ever been vaccinated against hepatitis B virus? Yes ( ); No ( ). If yes, Where , When How many times

13) Liver symptoms: Right upper abdominal discomfort or fullness ( ) fatique ( ), weight loss ( ) recurrent joint pains ( ), yellowness of the eyes in the past ( ) or at present ( ) others (please specify)

14) Laboratory results: HBsAg: HBsAb HBeAg $\mathrm{HBeAb}$ $\mathrm{HBcAb}$

Serum ALT AST ALP HB viral load

Other findings 